Fischer, K. W. (2008). Dynamic cycles of cognitive and brain development: Measuring growth in mind, brain, and education. In A. M. Battro, K. W. Fischer \& P. Léna (Eds.), The educated brain (pp. 127-150). Cambridge U.K.: Cambridge University Press.

\title{
8 Dynamic cycles of cognitive and brain development: Measuring growth in mind, brain, and education
}

\section{Kurt W. Fischer}

\section{Overview}

Since the seminal work of fean Piaget on the relation between knowledge and general biology, researchers have started to understand the basic neurocognitive processes in the unfolding of human development. In particular, recent dynamic growth models illuminate the complex, interrelated changes that take place during brain growth, cognitive development, and learning. Neurocognitive development should be conceived not as a ladder of successive stages but as a complex network of interactions and attractors, convergent and divergent paths, nested cycles, stabilities and instabilities, progressions and regressions, clusters of discontinuities and stable levels of performance. Cycles of cortical development and cycles of cognitive performance seem to be related. In particular the relationship becomes most visible with optimal functioning of the cognitive system, such as when a good teacher or textbook supports a student's performance. A series of discontinuities in optimal cognitive growth define a ten-level developmental scale, which has many potential educational implications. More generally, the systematic growth cycles of cognition and brain have many implications for education, which are sometimes not straightforward. It is essential to the future of education that teachers become involved in neurocognitive research and neuroscientists discover the great theoretical and practical challenge of working in schools.

The Editors

Most scientists and teachers find it obvious that cognitive development and brain development go together, and the enterprise of connecting mind, brain, and education starts with that assumption, as evident in most chapters of this book. Knowledge of brain development is growing at a phenomenal rate (Coch, Fischer, \& Dawson, in press; Dawson \& Fischer, 1994), and knowledge of cognitive development and learning is extensive, deep, and still building (e.g., Case, 1998; Fischer \& Bidell, 1998; Fischer \& Bidell, 2006; Piaget, 1983; Siegler, 1997). Yet understanding of how cognitive and brain development relate has been 
minimal. Many brain characteristics - number of neurons and synapses, brain mass, myelination, brain activity, and so forth - change systematically as children grow up. Simultaneously children's actions, speech, concepts, problem solving, social skills, motivation, and emotions develop. All these various changes are globally correlated, but the correlations are not very informative because everything is changing in parallel. Scientists who seek to understand brain-behavior relations and educators who want to use cognitive neuroscience to improve education need ways of finding and analyzing meaningful connections between changes in brain and behavior, moving beyond the finding that characteristics go generally up (some go generally down) with age. Despite these limitations of scientific knowledge, public expectations about relating brain science to educational practice are running far ahead of the realities of scientific knowledge (chapter by Bruer; Fischer, Immordino-Yang, \& Waber, 2006).

Meaningful approaches to relating brain and cognitive development are beginning to emerge, however. In one promising arena, the new tools of dynamic systems analysis have combined with the discovery of growth cycles in cognitive and brain development to provide a foundation for moving beyond the difficulties of analyzing brain-behavior relations. Dynamic systems theory provides tools for analyzing complex patterns of change in individual people, in contrast to traditional tools that focus on analyzing average patterns of change for groups, which smooth out the interesting complexities of individual change (chapter by van Geert \& Steenbeck). Research shows that individuals grow in complex patterns, showing not linear change but cycles of jumps and drops (DawsonTunik, Commons, Wilson, \& Fischer, 2005; Fischer \& Bidell, 2006; Molenaar, 2004). These discontinuities and complex patterns provide valuable tools for analyzing development of brain and behavior because scientists can examine relations between the patterns. Evidence is accumulating for cycles of brain growth, cycles of cognitive development, and cycles in learning. All three cycles seem to involve a common process of growth, and one outcome of the research on these growth patterns is the discovery of a general ruler for development and learning that has many uses in educational assessement and practice.

\section{Growth cycles and rulers for brain and behavior}

In living organisms, growth generally occurs through cycles. A prime example is the growth of the cortex, which grows six layers in a cyclical process of neuron generation and migration, as described by Rakic (1971; 1988). A single growth process thus produces six distinct layers in which cells for different layers end up with vastly different functions, even 
though they are all created by the same process. The process begins as the germinal layer in the embryo's ventricular zone grows new cells in large numbers, and each cell migrates along a ladder created by a glial cell to its destination. The first cells to migrate stop at the first layer of the cortex (dubbed layer six because it is the sixth layer from the top of the cortex, although it is the first one in development of the embryo). After that layer fills up, the cells continue to a higher point to become the second layer, which in turn becomes filled. The next cells then stop at what becomes the third layer, which again becomes filled. This process continues until the six layers of the cortex are all laid down. In this way one growth process creates cortical layers that end up with very different properties and functions. Within a cortical column, the six layers relate to each other hierarchically, with the lower layers ( 5 and 6 by conventional numbering) performing more basic functions, such as dealing with basic sensory and motor inputs and outputs, and the higher layers (1 and 2) performing functions that combine, integrate, or differentiate the signals from the lower ones.

Analogous growth cycles seem to occur in brain and cognitive development over time, based on the still young research on growth patterns of brain activity and the more mature evidence on cognitive performance. One of the simplest indexes of the cyclical pattern is that growth occurs with a series of discontinuities - spurts or drops in the simplest case, such as the widely documented spurts in language in the second year (Reznick \& Goldfield, 1992). In a study of spontaneous language production in Dutch children Ruhland and van Geert (1998) found that most children showed rapid jumps in performance for specific word categories in the vicinity of 24 months of age, such as the spurt produced by Tomas for use of personal pronouns, shown in Figure 8.1.

This spurt at around 24 months comprises one pass through the growth cycle for cognitive development, which moves through a series of spurts in performance starting in early infancy and continuing into the 20 s (Fischer \& Bidell, 2006), as shown for the upper line in Figure 8.2. Infants, children, adolescents, and young adults all move through periods when their skills are leaping forward at a fast pace, especially under conditions that support optimal performance (upper line). In more ordinary performance, where they are not pushing the limits of their capacity, they commonly show either linear growth or unsystematic change (lower line). The graph presents a summary portrait of the growth patterns for the advanced abstract skills that develop during adolescence and early adulthood (Fischer, Yan, \& Stewart, 2003).

These complex growth patterns combined with methods from dynamic systems theory provide powerful tools for use in research on brain 




Source: Data from Ruhland \& van Geert, 1998

Figure 8.1 Developmental spurt in use of personal pronouns by Tomas, a Dutch boy.

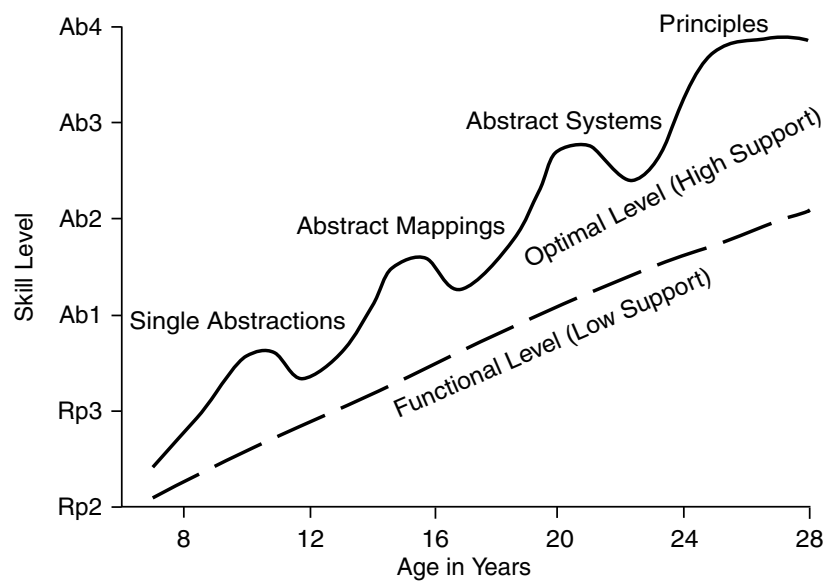

Figure 8.2 Cyclical spurts for cognitive development under optimal conditions. 
development and education, because they follow a common scale across domains. Skills in different domains demonstrate discontinuities along the same scale (Dawson-Tunik et al., 2005; Fischer \& Bidell, 2006). The results are especially strong and clear for cognitive development and learning, where research has clearly demonstrated a single common scale for skill complexity across diverse contents and with different methods for assessing patterns of change. Cognitive development moves along this scale whatever the domain, just as temperature follows one scale whether the object measured is a sick child, a glacier, a boiling pot of water, a volcano, or the surface of the sun. The complexity scale provides a useful ruler for educational assessments, applying for different domains, for learners and teachers, for tests and curricula (Bidell \& Fischer, 1992; Dawson-Tunik \& Stein, in press). It has proved useful even for tracking the ups and downs of learning a specific task, which is commonly called microdevelopment (Granott, Fischer, \& Parziale, 2002).

Understanding the growth patterns behind the scale requires first addressing a common misconception about development. Most people assume unconsciously that development involves progression along a ladder from one stage to the next. However, children and likewise adults develop not along a ladder but along a web of many strands. The common complexity scale across domains does not mean that development occurs in ladder-like stages. Figure 8.3 illustrates the web for three domains of development in adolescents and young adults - mathematics, self-in-relationships, and reflective judgment (Fischer et al., 2003). An individual constructs separate skills for each domain, including several different strands within each. All strands move along the same complexity scale, but the skills in one strand are independent of those in another. Sometimes strands differentiate into new, separate strands, and at other times they combine to form a new integrated strand. For some purposes skills in different domains such as reflective judgment and conceptions of self can be treated as simply separate, but as development proceeds, people often combine strands from different domains, connecting for example conceptions of self as a student with conceptions about how they know that something is true (the bases of knowledge - reflective judgment). In either case, the same complexity scale characterizes development along each strand, even though the strands involve separate skills. The same ruler measures the complexity, but this common ruler does not imply that all the skills are the same, any more than a common temperature reading means that a person with a given temperature contains the same heat energy as a summer day with that temperature. 
Mathematics Self in Reflective judgment

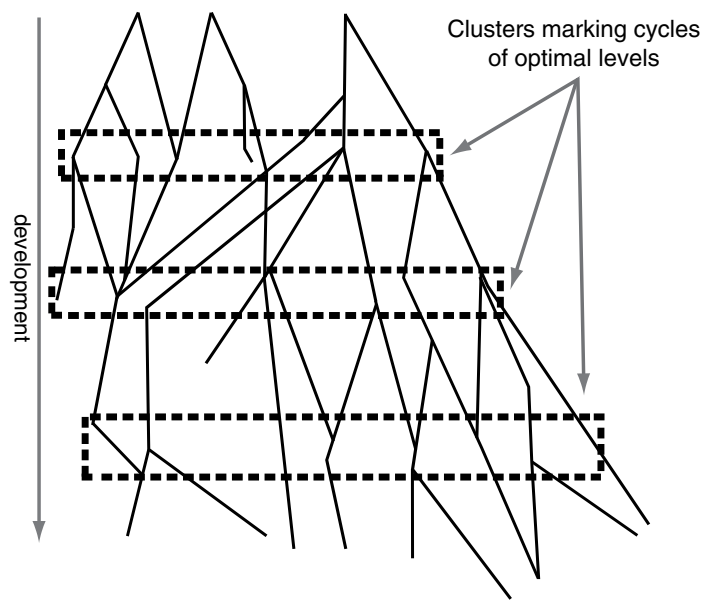

Figure 8.3 A developmental web of many strands with clusters of discontinuities for three skill levels.

The growth cycle of skill construction appears in the web as clusters of discontinuities - angles, joinings, and separations of lines within the boxes marking the zones in which three new optimal levels emerge. These clusters capture changes for optimal performance, while ordinary, nonoptimal performance takes place at lower points along the strands. That is, the same person in the same domain or strand shows a different developmental level depending on whether he or she is performing at optimal or functional level (as shown in Figure 8.2). People do not act consistently at one level, even for a familiar domain such as conceptions of self. Their skills vary in complexity from minute to minute depending on contextual support, motivation, fatigue, and other factors.

\section{Cycles of cognitive development}

Cognitive development moves through ten levels between 4 months of age and early adulthood. The levels from childhood to adulthood, which are most relevant for education, are summarized in Table 8.1. Among the simplest, most compelling evidence for the levels is the spurts and drops in performance that occur for optimal performance at specific ages. Research on arithmetic, self concepts, reflective judgment, moral reasoning, classification, conservation, and many other tasks shows these 
Table 8.1 Developmental levels during the school years: optimal \& functional.

\begin{tabular}{lcl}
\hline \hline Level & Optimal & Functional $^{\star}$ \\
Rp1 Single Representations & 2 years & 2 to 5 years \\
Rp2 Representational Mappings & 4 & 4 to 8 \\
Rp3 Representational Systems & 6 & 7 to 12 \\
Rp4/Ab1 Single Abstractions & 10 & 12 to 20 \\
Ab2 Abstract Mappings & 15 & 17 to 30 \\
Ab3 Abstract Systems & 20 & 23 to 40 , or never for many domains \\
Ab4/P Single Principles & 25 & 30 to 45 , or never for many domains \\
\hline \hline
\end{tabular}

*Ages for functional levels vary widely \& are coarse estimates, based on research by Dawson, Fischer, Kitchener, King, Kohlberg, Rest, \& others. Levels are highly related to education.

spurts and drops marking the onset of capacities to build skills at each of the levels.

In a study of concepts for arithmetic operations, adolescents demonstrated spurts under optimal conditions for three levels - single abstractions, abstract mappings, and abstract systems (Fischer, Kenny, \& Pipp, 1990). Students between 9 and 20 years of age from diverse schools as well as a university in a mid-Western American city performed a set of arithmetic problems, such as $7+7+7=21,3 \times 7=21,5+9=14$, and $14-9=5$. They then answered questions that required them to explain the operations of addition, subtraction, multiplication, and division, and then the relations between the pairs of operations, such as addition and multiplication, or addition and subtraction. What is multiplication, and how do the problems that were calculated fit the definition of multiplication? How does multiplication relate to addition, and how do the problems involve that relation? Students first did the calculations and offered the explanations under low-support conditions, simply answering the questions on their own. Then they were provided with good, prototypic answers to the questions about the operations (high support), which they were asked to explain in their own terms. At the end of the session they were told that they would return in two weeks to do the problems again, and they should think about the questions. When they returned, they again did the problems and answered the questions first with low support and then with high support.

Students showed dramatic jumps in performance under optimal conditions at specific ages, as shown in Figure 8.4 for mappings relating pairs of arithmetic operations. The spurts were especially abrupt in the second session, two weeks after the first one, when students had not only high 


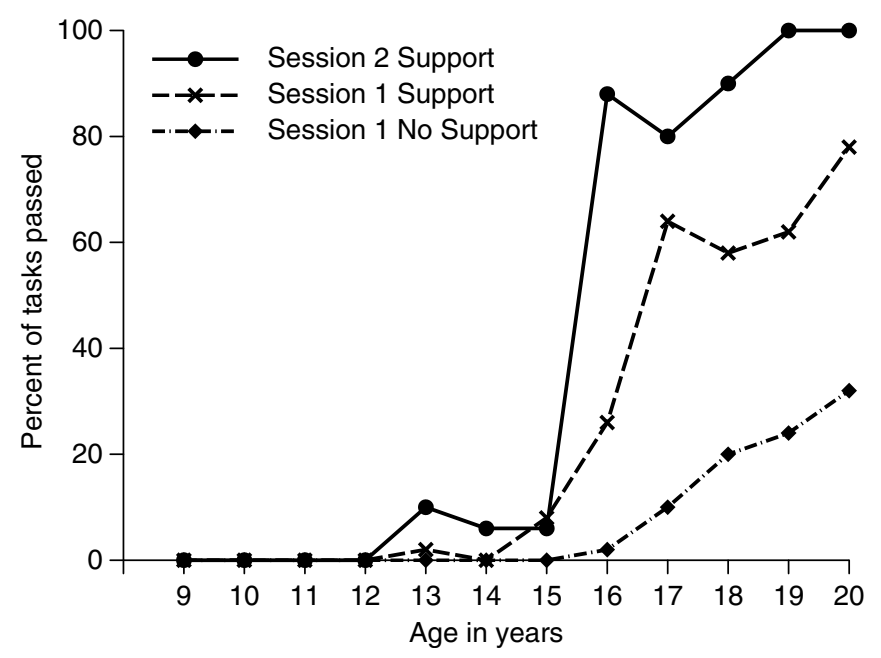

Figure 8.4 Spurts for mappings of arithmetic operations.

support but also days to practice and think about the questions. Students were asked to explain the relations between addition and subtraction, addition and multiplication, multiplication and division, and subtraction and division (two versions of each question for a total of eight tasks). When they were simply asked, without any support or practice (Session 1 No Support), they showed very low levels of performance - near zero until age 16 and reaching only 32 percent correct at age 20 . However, when they were given support (Session 1 Support), their performance jumped sharply between 15 and 17 years. The opportunity to think about the problems for two weeks led to an even more abrupt spurt, from 6 percent at age 15 to 88 percent at age 16 (Session 2 Support). This study was the first test of a spurt predicted solely from dynamic skill theory without any prior evidence, and Figure 8.4 shows that the finding was strong and unambiguous.

Besides the spurt for mappings, the graph also shows another developmental phenomenon with strong educational relevance - later-level consolidation: A new kind of skill, such as relations of arithmetic operations or concepts for determining truth, emerges at one level; but it is only consolidated to produce consistent performance at a later level several years later, when the various components can be coordinated and interconnected. In the arithmetic study, the two curves showing spurts both leveled out for a few years after 16 and then spurted again to even better performance at about age 20. Such a second spurt occurs commonly in cognitive 
development, reflecting the emergence of the next level, which in this case is abstract systems (Ab3). When a new level emerges, performance jumps above zero, but it typically jumps to much less than perfect performance. For example, with reflective judgment (explaining the bases of knowledge in complex dilemmas), students' performance jumped to only about 50 percent correct with the first emergence of a level (Kitchener, Lynch, Fischer, \& Wood, 1993). Only five years later, with emergence of the next level, did performance approach 100 percent.

The series of discontinuities in cognitive growth define a ten-level developmental scale - three levels of sensorimotor actions plus the seven levels in Table 8.1. In addition, a different set of methods have produced independent evidence of the same scale of seven levels in Table 8.1. Theo Dawson (Dawson \& Wilson, 2004; Dawson-Tunik et al., 2005) pioneered this research, using Rasch analysis to scale item difficulty in extensive data sets based on interviews, standardized tests, essays, and other written materials. Rasch scaling detected exactly the same seven-level scale in these data sets, demonstrating clustering of items by complexity level and gaps along the complexity scale between the clusters. The clustering holds even for adults, where age is not a factor in the ordering of items.

The successive levels that develop as shown in Table 8.1 indicate one kind of growth cycle, a recurring cluster of spurts in performance with emergence of each new cognitive level. Analogous to the growth cycle that produces successive layers of cortex through the common process of neuron generation and migration, the cognitive levels build over time based on a common growth process, producing a qualitatively new skill structure at each level.

Within these levels a second kind of growth cycle appears as well - a repetitive pattern of types of coordination of components that groups the levels into what are called tiers. This cycle first became evident in research when coders made common errors that mixed up, for example, a 5-yearold's simple relations of concrete roles with the more abstract relations of a 15-year-old (Fischer \& Elmendorf, 1986). Five-year-olds relate roles of mother with child or of doctor with patient, as when they tell stories with standard specific interactions between mother and child. Fifteen-yearolds relate instead broad, abstract roles of mother with child or doctor with patient. They describe the mother and child roles in society, for example, instead of limiting themselves to a specific, prototypical mother-child interaction. This combination of similarity and difference reflects a repetitive cycle of skill levels, a tier.

In general, development moves through at least three repetitive cycles from early infancy to adulthood. In each cycle or tier, a child or adult first controls a single unit of behavior - a single action, representation, or 


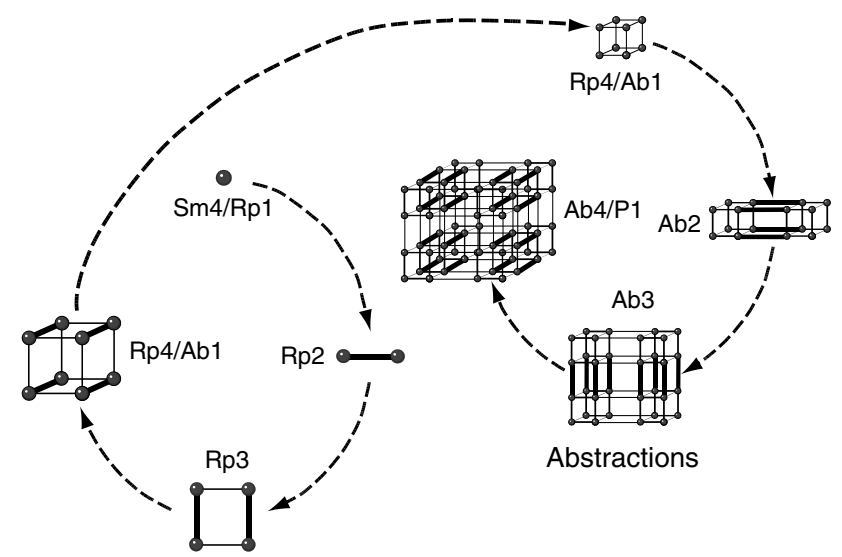

Representations

Figure 8.5 Developmental cycles for tiers of representations and abstractions.

abstraction for the sensorimotor, representational, and abstract tiers, respectively (Fischer, 1980; Fischer \& Bidell, 2006). Then the person relates at least two such units to form a mapping of actions, representations, or abstractions. Next the person coordinates at least two mappings to form a system. Finally with the fourth level in a tier, the person integrates at least two systems to form a system of systems, which generates a new kind of unit: Action systems generate single representations. Representational systems generate single abstractions. Abstract systems generate single principles. (There is no evidence to date of emergence of new levels beyond single principles.) Figure 8.5 illustrates this cycle for the representational and abstract tiers with the metaphor of building blocks, in which the simple blocks for representations eventually create a new kind of more complex building block to begin the capacity to think abstractly. I suspect that growth cycles of this kind are pervasive in cognitive and brain development, and I will propose several cycles for brain development that by hypothesis are related to these cycles of cognitive development.

\section{Cycles of cortical development}

Most research on the structure and development of the brain has focused on local, microscopic anatomy and physiology, such as how single 
neurons and synapses function. For connecting to education, the big picture of how the brain functions and changes with development is more obviously relevant. Although research on the brain system has been relatively sparse, it is growing rapidly, and there are sufficient findings to establish some key facts about brain development and to build initial models of cycles of brain growth (Fischer \& Rose, 1994).

The first established fact about brain development - of which many scientists and educators remain unaware - is that the brain and its parts generally grow in spurts, as do other body systems (Blinkov \& Glezer, 1968; Fischer \& Rose, 1994; Lampl, Veldhuis, \& Johnson, 1992; Noonan, Farnum, Leiferman, Lampl, Markel, \& Wilsman, 2004; Thatcher, 1994). The smooth growth curves shown on pediatric charts work only for averages of many children. Individual children grow in fits and starts.

These discontinuities are evident in many different measures of brain anatomy and activity, including cortical thickness, synaptic density, cortical electrical activity, and cortical connectivity. One of the simplest characteristics that shows this pattern of spurts and drops is the energy in the electroencephalogram (EEG), which is measured by calculating the area under the curves generated by electrical activity. In a classic study Matousek and Petersén (1973) measured EEG for people between 1 and 21 years of age in Sweden. The relative energy (energy in one frequency band for a cortical region divided by energy in all bands for that region) showed highly systematic growth curves, as shown in Figure 8.6 for the alpha band measured in the occipital-parietal region. Growth proceeds consistently upward, but there are recurring spurts (marked by the black dots in Figure 8.6), plateaus, and slight drops, reminiscent of the growth curves for development of arithmetic, reflective judgment, and other cognitive skills (Figures 1, 2, and 4). (Note that for some frequency bands (notably theta and delta) the growth curves go consistently downward, moving in similar fits and starts. Also, the form of the growth curves varies depending on the cortical region; for example, spurts during adolescence are much stronger in the prefrontal region than in the occipital region (Hudspeth \& Pribram, 1992).)

Remarkably the ages of the spurts for EEG energy correspond closely with the ages for cognitive spurts, as evident in comparisons of Figure 8.6 and Table 8.1. The correspondence is so close that it suggests a linkage between the two dynamic growth processes. This finding first inspired the simple form of the brain growth hypothesis: that cortical growth spurts reflect the emergence of new skill levels. However, most studies that show these spurts in brain or cognitive development measure only one brain or cognition - not both, which means that few data exist to test whether the two in fact relate in developing individuals. Fortunately a 


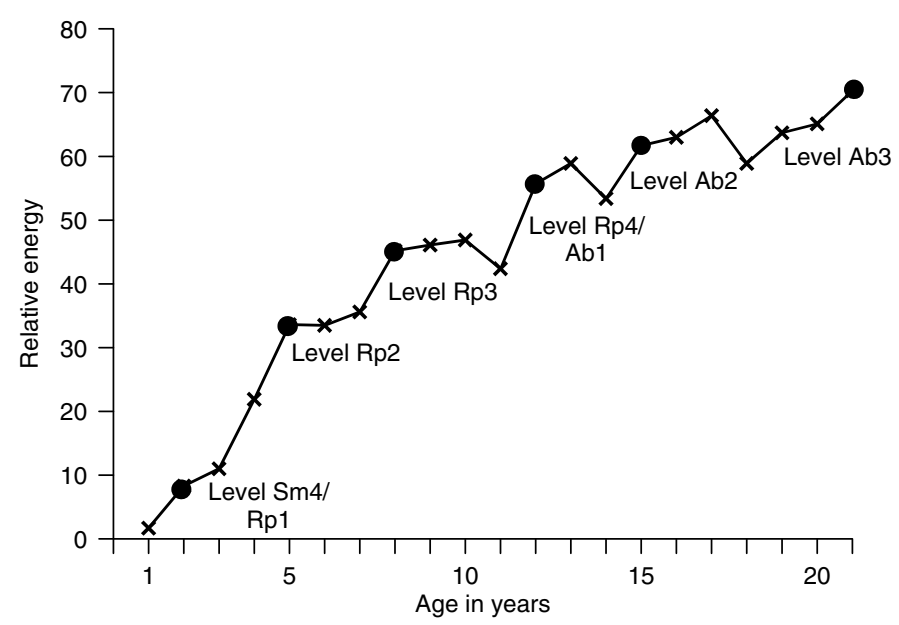

Figure 8.6 Development of relative energy in alpha EEG in occipitoparietal area.

small number of studies do measure both brain and cognitive development, and they support the brain growth hypothesis (Bell \& Fox, 1994; Bell \& Fox, 1996; Stauder, 1999; van der Molen \& Molenaar, 1994), but clearly more research is required to test the correspondence fully.

These phenomena suggest a simple growth model of correlated successive spurts in cortical activity and cognitive capacity, but they raise questions about the nature of the brain reorganizations with each spurt as well as the relation to the cognitive reorganizations in the growth cycles shown in Figure 8.5. My colleagues and I have created a model of growth of cortical networks - the network-growth hypothesis - based on existing research, especially the findings of Thatcher (Hanlon, Thatcher, \& Cline, 1999; 1992; 1994), Matousek and Petersén (1973), Hudspeth and Pribram (1990; 1992), and Somsen (Somsen, van ' $t$ Klooster, van der Molen, van Leeuwen, \& Licht, 1997). Besides EEG energy, the other most important measures from these findings involve EEG coherence, the correlation between electrical wave patterns in two regions. Correlated wave patterns indicate an active connection between two regions. Uncorrelated wave patterns indicate no active connection.

Explanation of the neural-network model requires describing the general layout of cortical areas assessed by EEG and other brain imaging techniques. Figure 8.7 diagrams the brain viewed from the top, with the nose marking the front of the head and the gray area indicating the prefontal cortex, which plays an especially important role in cortical networks. The 


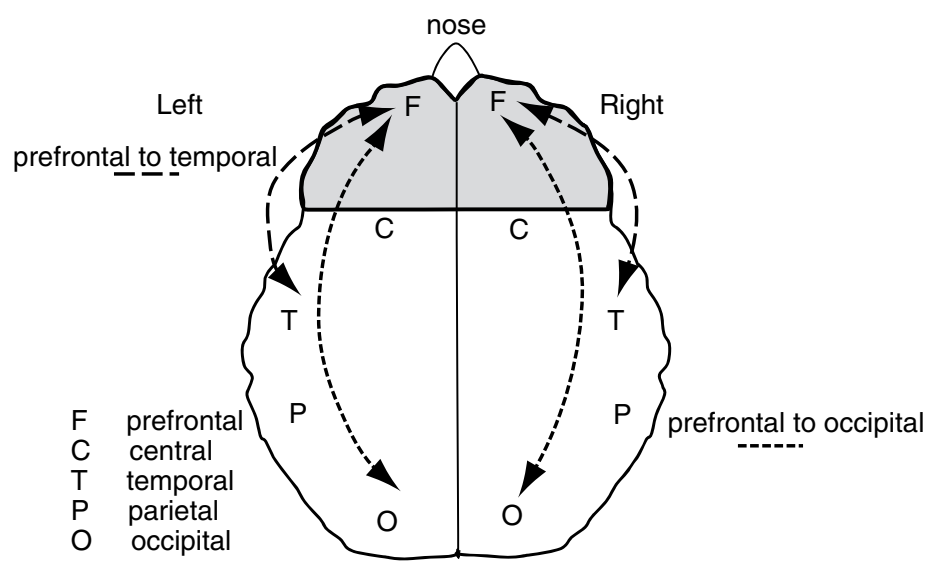

Figure 8.7 Top view of cortex illustrating some network connections.

regions of the cortex are given standard names listed in the diagram: left and right hemispheres, and within each hemisphere areas called prefrontal $(\mathrm{F})$, central (C), temporal ( $\mathrm{T})$, parietal $(\mathrm{P})$, and occipital $(\mathrm{O})$. Neural fibers (axons) connect parts of the cortex even across long distances, such as the prefrontal-occipital connections marked by the long arrows. Shorter connections are also important in neural networks, such as the prefrontaltemporal connections marked by the shorter arrows as well as connections within a cortical region, such as prefrontal-prefrontal connections (not shown). Evidence indicates that the large majority of active network connections occur within a hemisphere, as indicated by the arrows.

According to the network-growth hypothesis, the changes in energy shown in Figure 8.6 arise from developmental changes in neural networks in the brain, developments that come about through a cyclical process of rewiring and retuning networks. This growth process moves around the cortex systematically in a manner similar to that suggested by Thatcher (Hanlon et al., 1999; 1994) and illustrated in Figure 8.8 for the cognitive levels Rp3 and $\mathrm{Ab} 1$ that emerge at about 6 and 10 years. The prefrontal cortex leads the way, since empirical evidence indicates that the large majority of systematic changes with age in networks involve connections between the prefrontal cortex and other regions. Thatcher's data suggest that growth dominates in one part of the cortex at a given time, but it undoubtedly occurs less saliently in other places as well. Also, the diagram represents the hypothesized normative pattern, but different people are likely to show different patterns in the growth cycle. Research clearly shows, for instance, differences between males and females (Hanlon et al., 1999). 


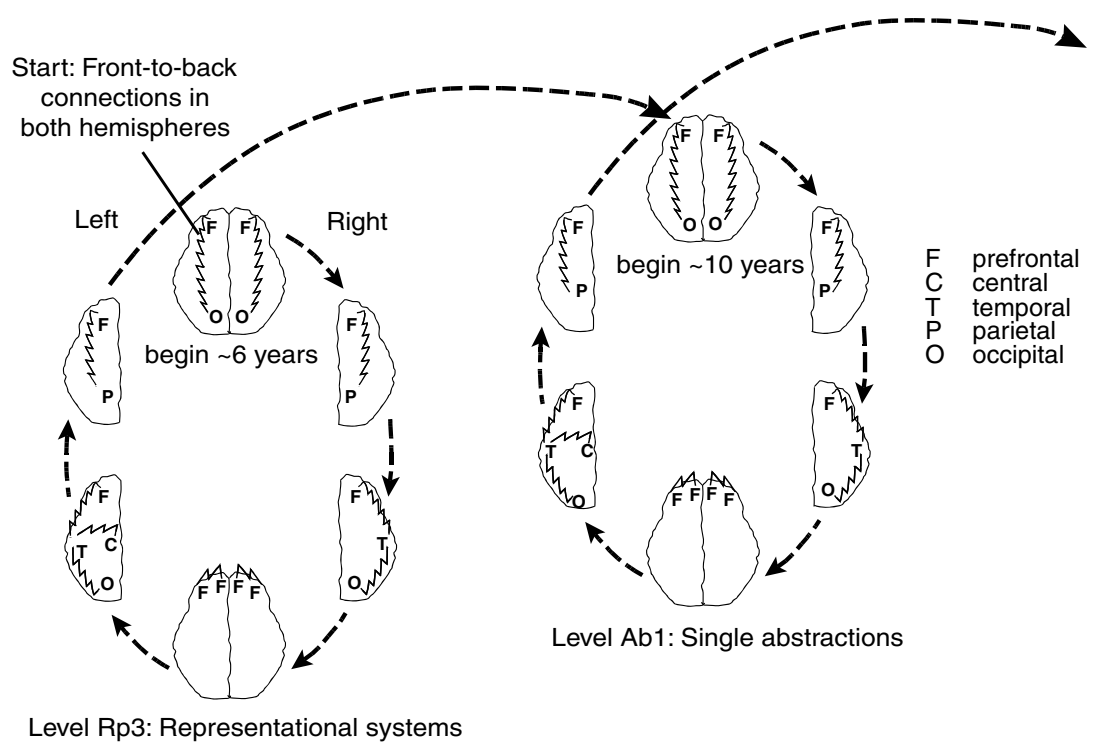

Figure 8.8 Cortical network cycle for two successive cognitive levels.

At the top of the diagram, front-back (prefrontal-occipital) connections grow more strongly than other connections as the level of representational systems Rp3 begins to develop. Gradually over several years the leading edge of growth of connections moves around the cortex, starting with the right hemisphere, where it becomes more local over time, tuning shorter connections. Halfway through the cycle, at the bottom of the diagram, the leading edge moves to the prefrontal cortex, as growth of local connections there predominate. Next it moves into the left hemisphere, starting more local and gradually moving toward longer connections until it returns to the longest, frontal-occipital connections. Here it begins the process over again, as the level of single abstractions Ab1 starts to develop. Eventually the cycle repeats, restructuring the network for the capacity of single abstractions, until eventually it completes, and the next level begins, abstract mappings Ab2.

According to the hypothesis, the network cycle corresponds to periods when particular types of learning and developmental changes occur, such as spurts in a major skill. In two studies, Martha Ann Bell has shown exactly such a relation - spurts and drops in coherence for specific cortical regions related to growth of major skills in infancy (Bell, 1998; Bell \& Fox, 1996). In her ambitious study of the onset of crawling, infants who 
were beginning to crawl displayed high coherence connecting frontal, occipital, and parietal regions, especially in the right hemisphere. As the infants became skilled crawlers, coherence dropped. Similarly, in a case study an infant showed high frontal-temporal coherence, especially in the left hemisphere, as she focused on babbling to produce many syllable-like sounds. The left temporal region plays an important role in language in most older children and adults.

For the minority of people who use the right hemisphere more prominently for language, the growth pattern for coherence should be different, of course. Likewise in general, individual differences in abilities and patterns of learning with age should correspond to cycle differences, based on the network-growth hypothesis. Just as infants who crawl late show a later spurt in frontal-occipital and frontal-parietal coherence, children who develop abstract thinking (Ab1 and beyond) late or learn to read late or suddenly begin to work hard at learning a sport should show parallel changes in growth of coherence in particular regions.

For cognitive development, the cycle that produces cognitive levels is nested within the wider cycle for tiers (Figure 8.5). Likewise, by hypothesis, the cycle for growth of networks shown in Figure 8.8 is nested within a larger cycle of growth of energy, coherence, and other brain characteristics that relate to tiers - the nested network hypothesis. For example, prefrontal energy seems to surge when a new tier emerges according to the analyses of EEG energy by Hudspeth and Pribram $(1990 ; 1992)$. Also, the highest spurts in energy move around the cortex systematically, according to the evidence to date. In addition, the oscillation patterns of coherence for specific cortical connections shift in correspondence with the movement into a new cortical-network cycle (Thatcher, 1994). Presumably, as yet unspecified shifts in network connections and other brain properties co-occur with the peak shifts.

According to the nested network hypothesis, the peak energy in specific cortical regions shifts systematically as cortical network cycles change through a tier of levels, as shown in Figure 8.9. Note that the cortical network cycle is nested inside the peak-energy cycle in the diagram. The peak energy begins in the prefrontal cortex and then gradually moves around the cortex over long age periods as children grow new levels. The model in Figure 8.9 fits reasonably with the few data that are available: Growth of peak energy moves gradually from prefrontal to occipital, parietal, central, temporal, and then back to central, parietal, occipital, and prefrontal. A reasonable hypothesis is that the first peaks (right side of the diagram) are concentrated in the right hemisphere, and the later ones in the left hemisphere; but most of the published data do not contain 


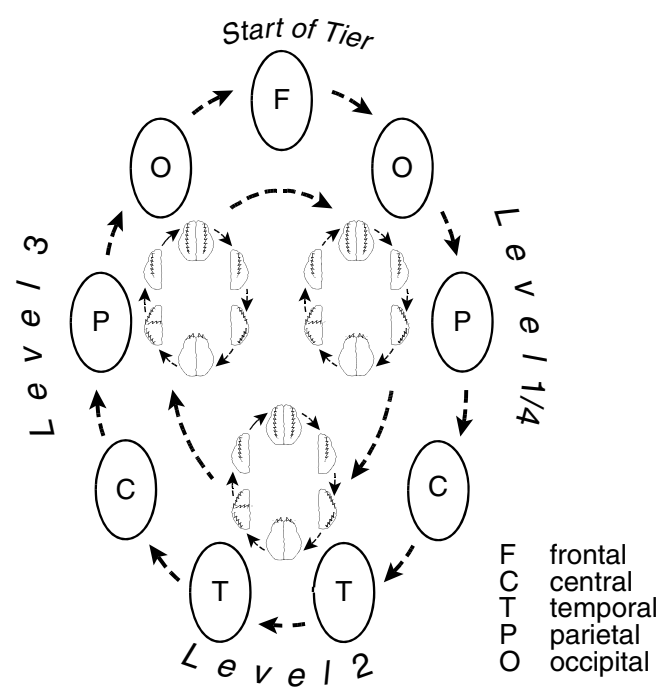

Figure 8.9 Peak energy cycle for tier, with nested network cycles.

the information for testing this specification. This nested cycle, like the network-growth cycle in Figure 8.8, presumably also corresponds to particular behavioral patterns, such as focusing on some skill domain or social-emotional issue.

\section{Cycles of learning: Backwards growth and microdevelopment}

The skill scale and the dynamic growth patterns that accompany it create several avenues for research on mind, brain, and education. Not only do they make possible research relating cognitive change with brain development, but they also provide a scale for measuring learning, teaching, curriculum, and other cognitive performances and products - a scale that has wide-ranging uses in educational assessment, evaluation, and practice (Dawson-Tunik \& Stein, in press; Schwartz \& Fischer, 2005). To illustrate this range of uses, I will focus on analysis of classroom learning as microdevelopment - growth of skill in school-related time periods, such as minutes, hours, days, and weeks during which students are supposed to learn.

When analyzed in terms of levels of constructed skill, students' performances show dynamic changes, with lots of increases and drops. 


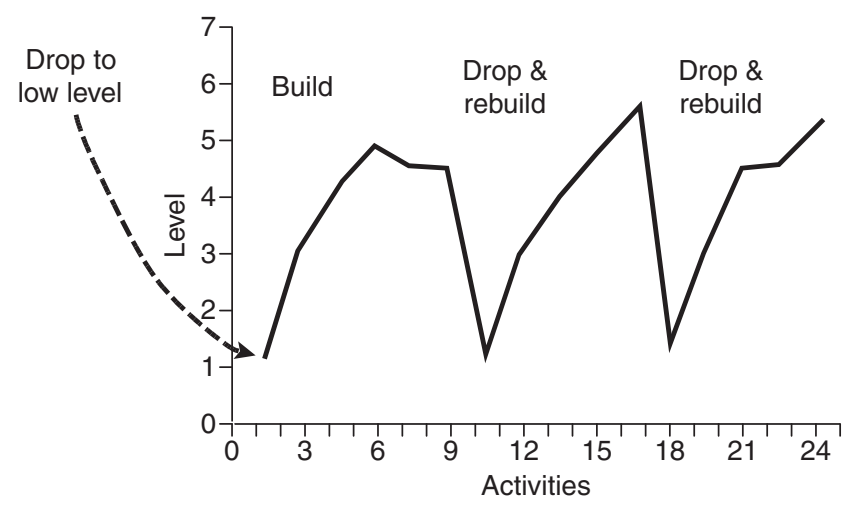

Figure 8.10 Building a new skill through repeated reconstruction, or scalloping. (Levels 1 to 3 involve actions, 4 to 6 involve representations, and 7 and above involve abstractions.)

These patterns of change reflect a cyclical process of skill construction, in which task characteristics interact with the student's level of expertise in the domain, among other things. The patterns also demonstrate that building of general knowledge (as opposed to learning specific "facts") is slow and hard. Much research shows that the kinds of knowledge taught in many high school and college courses - causes of the Civil War, the concept of energy in physics, analyzing evidence for evolution, writing a convincing essay - take much longer than a semester or a year to master (Fischer et al., 2003; Salomon \& Perkins, 1989).

The skill scale provides a method for measuring performance and learning across all these tasks and in any other domain and thus makes possible the assessment of any performance on a single metric as well as the comparison of performances across domains and tasks on that metric. In research on students learning over several months (middle school science students learning about magnetism, graduate students learning how to use a computer for statistical analysis, etc.) we found that learning occurs in recurring waves or scallops (Granott, 2002; Schwartz \& Fischer, 2005; Yan \& Fischer, 2002): A student starts with a low level of understanding a task or performance, such as using the computer to do a statistical analysis, and gradually builds up the skill in one situation, moving from actions to representations or from representations to abstractions, as shown in Figure 8.10. But the understanding collapses because of a change in the situation or for any of a hundred reasons. The student then builds up the understanding again and sustains it briefly, but once more it collapses. This process repeats itself many times as the 

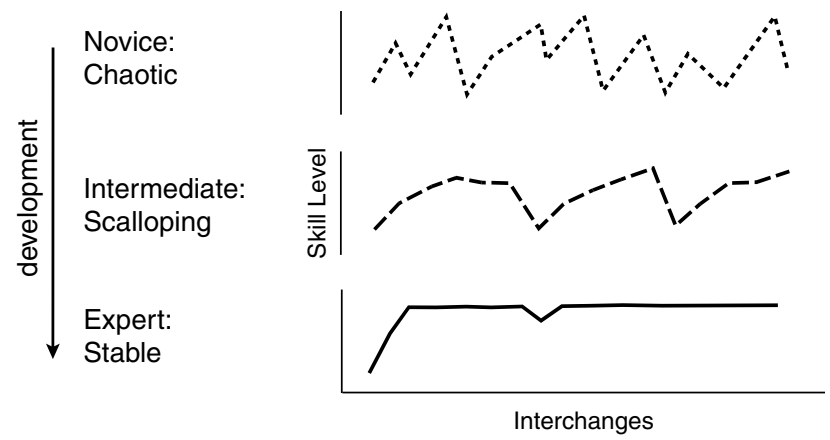

Figure 8.11 Growth curves for learning a task: novice, intermediate performers, and experts.

student learns a new skill or understanding, producing what is called a scalloping pattern in learning.

The collapses do not indicate difficulties. Instead they are normal and required, reflecting the need to build and rebuild a skill with variations so that the person can eventually sustain it in the face of changes in context and state. Commonly, mastering a task requires moving down to primitive levels of representations or even actions (similar to those of infants) as shown in Figure 8.10, so that the person can figure out the action characteristics of the task or situation. The human capacity to move down to such elementary levels provides enormous flexibility for intelligent adaptation, because people can learn new patterns of sensorimotor action required for success in a different kind of task. Moving to a low cognitive level for a new task comprises an essential part of intelligence.

The scalloping pattern only occurs some of the time in learning situations, however. It reflects the midpoint in the learning process, as shown in Figure 8.11. When students are novices - not familiar or comfortable with tasks that they need to do - their performance is even more variable than that in Figure 8.10 (Yan \& Fischer, 2002). Instead of building to a higher level skill over several activities, any relatively complex skill that they build quickly falls apart. Their performance vacillates up and down chaotically, as in the upper growth curve in Figure 8.11. As they acquire some knowledge of the task, they move from this chaotic pattern to the intermediate pattern of scalloping (the middle curve in Figure 8.11 and the curve in Figure 8.10), where they can sustain a higher level skill for a longer time but are still subject to abrupt, periodic collapse. 
After working at the task for some time (typically months or even years), they become experts who can sustain a stable, high level performance, as shown in the lower curve in Figure 8.11. Experts often require an initial period of exploring the task to understand its properties ("figure it out") before reaching a stable level, which leads to a gradual rise in level, as shown in the curve. Also, they occasionally encounter some event that leads to a drop in complexity level, which is typically shortlived.

In this way, learning involves not monotonic growth to higher levels of understanding but an extended cyclical process, in which a student repeatedly builds and rebuilds a performance. $\mathrm{He}$ or she moves from chaotic variation in skill level to repeated, gradual rebuilding of a skill (scalloping) and eventually to a relatively stable level of expertise. This analysis provides one example of how the skill complexity scale can illuminate learning and other educational activities. Perhaps it will also become possible to analyze brain activity as learning progresses, to ask how changes in brain activity relate to degree of skill and expertise. It is possible that some of the brain growth cycles described earlier will be evident as learning progresses in microdevelopment.

\section{Moving from growth cycles to educational implications}

The research relating cognitive developmental cycles and scaling to educational assessment is but one of many instances in which cognitive science findings contribute straightforwardly to educational research and practice. Connections between the cycles of brain development and education, however, are further from fruition. Eventually research directly connecting brain growth cycles with patterns of learning will illuminate the processes of learning, especially differences across individuals and contexts. For example, by hypothesis, differences in cortical network cycles relate to differences between children in both motivation to learn and effectiveness of learning in specific domains, such as spatial reasoning, mathematics, and literacy.

At present, however, efforts to link brain development research to education raise serious concerns because of carelessness and excess in "application" (chapter by Bruer this volume; Fischer et al., 2007). Journalists, educators, and even brain scientists too readily leap from a brain research finding to an "implication" for education - which is typically nothing more than seat-of-the-pants speculation. An important case of this kind of excess and its dangers took place in the $1970 \mathrm{~s}$ and 1980 s, when a few scientists uncovered the first evidence of head 
growth spurts (Epstein, 1974) and then brain activity growth spurts (Fischer \& Rose, 1994; John, 1977). Within a few years some scientists and educators were leaping to conclusions wholly unwarranted by the data, such as that students could not learn anything new during plateau periods between brain growth spurts. They recommended to a number of school districts that curricula be changed to introduce no new concepts during the normative age periods of brain growth plateaus, because no new learning would occur then, they asserted (Epstein, 1978; Fischer \& Lazerson, 1984). The cognitive evidence, including data on school performance and learning, never supported this speculation, but a number of school systems in North America took the recommendations seriously because the proponents claimed that they came from brain science. Several of us fought against these specious claims for several years until finally the troublesome efforts faded away.

Another common error has been to leap from evidence of critical periods in brain development - a limited window of time during which a specific experience shapes brain function - to implications about when people can and cannot learn to speak, read, do arithmetic, etc. (Bailey, Bruer, Symons, \& Lichtman, 2001; Snow \& Hoefnagel-Hohle, 1978). These claims too represent illegitimate conclusions that are not supported by careful research evidence.

Researchers and educators in mind, brain, and education need to use normal scientific caution in drawing conclusions for educational practice. That includes refraining from leaps to educational implications from brain research until there is direct evidence assessing learning and performance - evidence that links brain to behavior and behavior in turn to practice. For example, there is great promise that cycles of brain and cognitive growth will illuminate learning and educational practice, providing powerful new tools for analyzing students' learning patterns and differences and optimizing educational interventions. Already the research on cognitive growth cycles is bearing fruit in assessing and comparing learning patterns across domains and individuals as well as relating them to teaching and curriculum. However, the current state of knowledge does not allow direct extrapolation from brain growth cycles to educational practice. Building links among mind, brain, and education requires building reciprocal relations among cognitive science, biology, and education based in interactions of researchers and practitioners. As those links grow, questions and insights from educational practice will inform and enrich brain and cognitive science just as much as scientific findings will inform and enrich educational practice. 


\section{References}

Bailey, D. B., Jr., Bruer, J. T., Symons, F. J., and Lichtman, J. W. (eds.) (2001). Critical Thinking About Critical Periods. Baltimore, MD: Paul H. Brookes Publishing.

Bell, M.A. (1998). The ontogeny of the EEG during infancy and childhood: Implications for cognitive development. In B. Garreau (ed.) Neuroimaging in Child Psychiatric Disorders (pp. 97-111). Berlin: Springer-Verlag.

Bell, M. A. and Fox, N. A. (1994). Brain development over the first year of life: Relations between electroencephalographic frequency and coherence and cognitive and affective behaviors. In G. Dawson \& K. W. Fischer (eds.), Human Behavior and the Developing Brain (pp. 314-345). New York: Guilford Press.

(1996). Crawling experience is related to changes in cortical organization during infancy: Evidence from EEG coherence. Developmental Psychobiology, 29, 551-561.

Bidell, T.R. and Fischer, K.W. (1992). Cognitive development in educational contexts: Implications of skill theory. In A. Demetriou, M. Shayer, \& A. Efklides (eds.), Neo-Piagetian Theories of Cognitive Development: Implications and Applications for Education (pp. 9-30). London: Routledge \& Kegan Paul.

Blinkov, S. M. and Glezer, I. I. (1968). The Human Brain in Figures and Tables. New York: Plenum Press.

Case, R. (1998). The development of conceptual structures. In D. Kuhn and R.S. Siegler (eds.), and W. Damon (Series ed.), Handbook of Child Psychology: Vol. II. Cognition, Perception, and Language. New York: Wiley.

Coch, D., Fischer, K. W., and Dawson, G. (eds.) (2007). Human Behavior, Learning and the Developing Brain: Normal Development (2nd edn.). New York: Guilford.

Dawson, G. and Fischer, K. W. (eds.) (1994). Human Behavior and the Developing Brain. New York: Guilford Press.

Dawson, T. and Wilson, M. (2004). The LAAS: A computerizable scoring system for small- and large-scale developmental assessments. Educational Assessment, 9, 153-191.

Dawson-Tunik, T.L., Commons, M., Wilson, M., and Fischer, K. W. (2005). The shape of development. European fournal of Developmental Psychology, 2, 163-195.

Dawson-Tunik, T. L. and Stein, Z. (in press). Cycles of research and application in science education. In K. W. Fischer \& T. Katzir (eds.), Building Usable Knowledge in Mind, Brain, and Education. Cambridge: Cambridge University Press.

Epstein, H. T. (1974). Phrenoblysis: Special brain and mind growth periods. Developmental Psychobiology, 7, 207-224.

(1978). Growth spurts during brain development: Implications for educational policy and practice. In J.S. Chall and A.F. Mirsky (eds.), Education and the Brain (Yearbook of the NSSE). Chicago: University of Chicago Press. 
Fischer, K. W. (1980). A theory of cognitive development: The control and construction of hierarchies of skills. Psychological Review, 87, 477-531.

Fischer, K. W. and Bidell, T. R. (1998). Dynamic development of psychological structures in action and thought. In R. M. Lerner (ed.) and W. Damon (Series ed.), Handbook of Child Psychology: Vol. I. Theoretical Models of Human Development (5th edn., pp. 467-561). New York: Wiley.

(2006). Dynamic development of action, thought, and emotion. In R. M. Lerner (ed.) and W. Damon (Series ed.), Handbook of Child Psychology: Vol. I. Theoretical Models of Human Development (6th edn., pp. 313-399). New York: Wiley.

Fischer, K.W. and Elmendorf, D. (1986). Becoming a different person: Transformations in personality and social behavior. In M. Perlmutter (ed.), Cognitive Perspectives on Children's Social Development. Minnesota Symposium on Child Psychology, 18, 137-178. Hillsdale, NJ: Erlbaum.

Fischer, K. W., Immordino-Yang, M. H., and Waber, D. P. (2007). Toward a grounded synthesis of mind, brain, and education for reading disorders: An introduction to the field and this book. In K. W. Fischer, J.H. Bernstein, \& M.H. Immordino-Yang (eds.), Mind, Brain, and Education in Reading Disorders (pp. 3-15). Cambridge, UK: Cambridge University Press.

Fischer, K. W., Kenny, S. L., and Pipp, S. L. (1990). How cognitive processes and environmental conditions organize discontinuities in the development of abstractions. In C. N. Alexander and E. J. Langer (eds.), Higher Stages of Human Development: Perspectives on Adult Growth (pp. 162-187). New York: Oxford University Press.

Fischer, K. W. and Lazerson, A. (1984). Research: Brain spurts and Piagetian periods. Educational Leadership, 41(5), 70.

Fischer, K. W. and Rose, S. P. (1994). Dynamic development of coordination of components in brain and behavior: A framework for theory and research. In G. Dawson and K. W. Fischer (eds.), Human Behavior and the Developing Brain (pp. 3-66). New York: Guilford Press.

Fischer, K. W., Yan, Z., and Stewart, J. (2003). Adult cognitive development: Dynamics in the developmental web. In J. Valsiner and K. Connolly (eds.), Handbook of Developmental Psychology (pp. 491-516). Thousand Oaks, CA: Sage.

Granott, N. (2002). How microdevelopment creates macrodevelopment: Reiterated sequences, backward transitions, and the zone of current development. In N. Granott and J. Parziale (eds.), Microdevelopment: Transition Processes in Development and Learning (pp. 213-242). Cambridge: Cambridge University Press.

Granott, N., Fischer, K. W., and Parziale, J. (2002). Bridging to the unknown: A transition mechanism in learning and problem-solving. In N. Granott and J. Parziale (eds.), Microdevelopment: Transition Processes in Development and Learning (pp. 131-156). Cambridge: Cambridge University Press.

Hanlon, H. W., Thatcher, R. W. and Cline, M. J. (1999). Gender differences in the development of EEG coherence in normal children. Developmental Neuropsychology, 16, 479-506. 
Hudspeth, W. J. and Pribram, K.H. (1990). Stages of brain and cognitive maturation. Fournal of Educational Psychology, 82, 881-884.

Hudspeth, W.J. and Pribram, K.H. (1992). Psychophysiological indices of cerebral maturation. International fournal of Psychophysiology, 12, 19-29.

John, E. R. (1977). Functional Neuroscience. Vol. II: Neurometrics. Hillsdale, NJ: Erlbaum.

Kitchener, K.S., Lynch, C.L., Fischer, K.W., and Wood, P.K. (1993). Developmental range of reflective judgment: The effect of contextual support and practice on developmental stage. Developmental Psychology, 29, 893-906.

Lampl, M., Veldhuis, J. D., and Johnson, M. L. (1992). Saltation and stasis: A model of human growth. Science, 258, 801-803.

Matousek, M. and Petersén, I. (1973). Frequency analysis of the EEG in normal children and adolescents. In P. Kellaway and I. Petersén (eds.), Automation of Clinical Electroencephalography (pp. 75-102). New York: Raven Press.

Molenaar, P.C. M. (2004). A manifesto on psychology as idiographic science: Bringing the person back into scientific psychology, this time forever. Measurement, 2, 201-218.

Noonan, K. J., Farnum, C. E., Leiferman, E. M., Lampl, M., Markel, M. D., and Wilsman, N.J. (2004). Growing pains: Are they due to increased growth during recumbency as documented in a lamb model? fournal of Pediatric Orthopedics, 24, 726-731.

Piaget, J. (1983). Piaget's theory. In W. Kessen (ed.) and P. H. Mussen (Series ed.), Handbook of Child Psychology: Vol. I. History, theory, and methods (pp. 103-126). New York: Wiley.

Rakic, P. (1971). Guidance of neurons migrating to the fetal monkey neocortex. Brain Research, 33, 471-476.

(1988). Specification of cerebral cortical areas. Science, 241, 170-176.

Reznick, J. S. and Goldfield, B. A. (1992). Rapid change in lexical development in comprehension and production. Developmental Psychology, 28, 406-413.

Ruhland, R. and van Geert, P. (1998). Jumping into syntax: Transitions in the development of closed class words. British fournal of Developmental Psychology, 16(Pt 1), 65-95.

Salomon, G. and Perkins, D. N. (1989). Rocky roads to transfer: Rethinking mechanisms of a neglected phenomenon. Educational Psychologist, 24, 185-221.

Schwartz, M. S. and Fischer, K. W. (2005). Building general knowledge and skill: Cognition and microdevelopment in science learning. In A. Demetriou and A. Raftopoulos (eds.), Cognitive Developmental Change: Theories, Models, and Measurement. Cambridge, UK: Cambridge University Press.

Siegler, R.S. (1997). Children's Thinking (3rd edn.). Englewood Cliffs, NJ: Prentice-Hall.

Snow, C. E. and Hoefnagel-Hohle, M. (1978). The critical period for language acquisition: Evidence from second language learning. Child Development, 49, 1114-1128.

Somsen, R. J. M., van 't Klooster, B. J., van der Molen, M. W., van Leeuwen, H. M. P., and Licht, R. (1997). Growth spurts in brain maturation during 
middle childhood as indexed by EEG power spectra. Biological Psychology, 44, 187-209.

Stauder, J.E. A. M., Peter, C. M., and van der Molen, M. W. (1999). Brain activity and cognitive transition during childhood: A longitudinal eventrelated brain potential study. Child Neuropsychology, 5, 41-59.

Thatcher, R. W. (1992). Cyclic cortical reorganization during early childhood. Special Issue: The role of frontal lobe maturation in cognitive and social development. Brain E Cognition, 20(1), 24-50.

(1994). Cyclic cortical reorganization: Origins of human cognitive development. In G. Dawson and K. W. Fischer (eds.), Human Behavior and the Developing Brain (pp. 232-266). New York: Guilford Press.

van der Molen, M. W. and Molenaar, P. C. M. (1994). Cognitive psychophysiology: A window to cognitive development and brain maturation. In G. Dawson and K. W. Fischer (eds.), Human Behavior and the Developing Brain (pp. 456-490). New York: Guilford.

Yan, Z. and Fischer, K. W. (2002). Always under construction: Dynamic variations in adult cognitive development. Human Development, 45, 141-160. 